\title{
Bamboo Usage in Orthopedic: An Attempt to Reconcile Materials Properties with the Biomechanics of Human Walking
}

\author{
Talya Carnrike ${ }^{1}$, Aruoture Egoh ${ }^{1 *}$, Kischa S. Reed ${ }^{2}$ and Peter N. Kalu ${ }^{1}$
}

${ }^{1}$ Department of Mechanical Engineering, FAMU-FSU College of Engineering, Tallahassee, FL 32310, USA

${ }^{2}$ Division of Physical Therapy, Florida A\&M University, Tallahassee, FL 32307, USA

\begin{abstract}
Background: This work is part of an ongoing study on the use of natural materials to provide low cost exoskeleton and orthopedic devices in general. An earlier work showed that fir, pine, oak and bamboo satisfied the requirements of the mid-stance of the Gait cycle which is about $10 \%$ of a person's total weight. In reality, there are eight determinants of the gait cycle and they involve pelvic rotation and tilt, in addition to foot mechanics, knee mechanics and lateral displacement of pelvis. Furthermore, during walking, the peak vertical ground reaction force can rise up to 1.2 times the body weight. Therefore, any replacement exoskeleton material is expected to withstand this amount of compressive force and the rotational torques as well as possess excellent fracture toughness.
\end{abstract}

Methods: The eight determinants of the gait cycle of normal walking were analyzed with along their consideration that during walking, the peak vertical ground reaction force can rise up to 1.2 times the body weight. The materials selection process utilized the Ashby's procedure and consists of four steps, namely: translation, screening, ranking and documentation. Additional assessment of the fracture toughness and formability of the materials were carried out.

Results: While all the natural materials satisfied the basic selection, process based on cost and weight, only oak and Moso bamboo fulfilled the additional requirement of strength and formability. Oak was however eliminated due to its characteristic low fracture toughness which means that it is unable to provide the weight bearing support in the stance phase.

Conclusion: All the natural materials studied satisfied the cost and weight requirements for low-cost orthopedic devices. However, only Moso bamboo with its characteristic high fracture toughness and formability can comfortably replace duralumin in exoskeleton.

\section{Background}

\section{Current exoskeletons}

This work presents a more comprehensive assessment of the use of natural materials in orthopedic application and it is a follow up on a previous paper which dealt with the use of low-cost material for exoskeletal application. Gait is fundamental to the quality of life [1]. Gait is essential to basic activities of daily living (ADLs) to one's ability to carry out functional tasks for independent living. For person's living with gait and balance disorders, gait abnormality can limit quality of function and create barriers on activity performance and participation [2]. This is particularly significant for the lower extremity (LE) amputee, where the major limitation is often the difficulty with walking $[2,3]$. In addition, the cost of prosthetic devices essential to restore function in people with gait dysfunction is not affordable to many. Depending on the type of prosthetic leg, the cost of prosthesis can typically range from $\$ 5,000$ for a basic prosthetic leg to above $\$ 70,000$ for an advanced computerized prosthetic leg and exoskeletons, and the prosthesis may only last anywhere from three to five years before requiring replacement related to conditions of wear and tear [3]. While continual adjustments and numerous replacements will be needed during the lifetime of the amputee; for the patient without health insurance, the long-term costs associated with prosthetic care may not be affordable. While prostheses are artificial devices used to replace missing body parts, exoskeletons work in parallel with the body to assist the user in their movements. Although both devices are primarily used for rehabilitation purposes, Exoskeletons can also be used as safety equipment. The exoskeletons that are used for safety equipment, assist workers in performing hazardous jobs with minimal injuries [4]. When used for rehabilitation purposes, the individuals in question are usually suffering from debilitating neurological or limb pathologies lacking sufficient strength, power, torque, and endurance [5]. Exoskeletons can be used to target the full body, upper extremities, and lower extremities [6]. Figures 1-4 presents the different types of exoskeletons used for lower extremities, and they are classified as powered, passive, pseudo-passive, and hybrid [5,7-10].

Obviously, exoskeletons enable people with serious mobility issues to leave their wheelchairs behind. The main issue is that the cost of a wheelchair is cheaper than an exoskeleton which is why health insurers don't see its benefit. When the price of the exoskeletons become comparable to that of a wheelchair then insurance companies will consider these devices for personal use. Physical therapy offices and large companies are the current exoskeleton customers. The high cost of exoskeletons can be attributed partly to the cost of the material it is made out of. Exoskeletons currently available are typically made of Duralumin (Al-2024 T6). Other materials investigated were either too heavy (steel) or too expensive (carbon fiber). In order to replace

"Corresponding Author: Aruoture Egoh, Department of Mechanical Engineering, FAMU-FSU College of Engineering, Tallahassee, FL 32310, USA; Tel: +1 850345 7857; E-mail: aruoture1.egoh@famu.edu

Citation: Carnrike T, Egoh A, Reed KS, Kalu PN (2020) Bamboo Usage in Orthopedic: An Attempt to Reconcile Materials Properties with the Biomechanics of Human Walking. Int J Phys Ther Rehab 6: 164. doi: https://doi.org/10.15344/2455$7498 / 2020 / 164$

Copyright: (C) 2020 Carnrike et al. This is an open-access article distributed under the terms of the Creative Commons Attribution License, which permits unrestricted use, distribution, and reproduction in any medium, provided the original author and source are credited. 
Citation: Carnrike T, Egoh A, Reed KS, Kalu PN (2020) Bamboo Usage in Orthopedic: An Attempt to Reconcile Materials Properties with the Biomechanics of Human Walking. Int J Phys Ther Rehab 6: 164. doi: https://doi.org/10.15344/2455-7498/2020/164
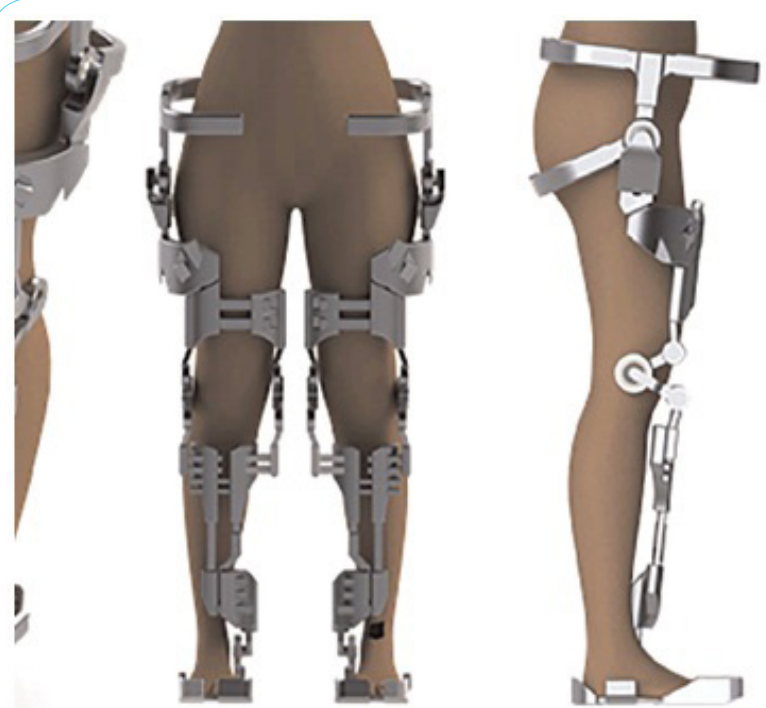

Figure 1: Powered exoskeleton [7].

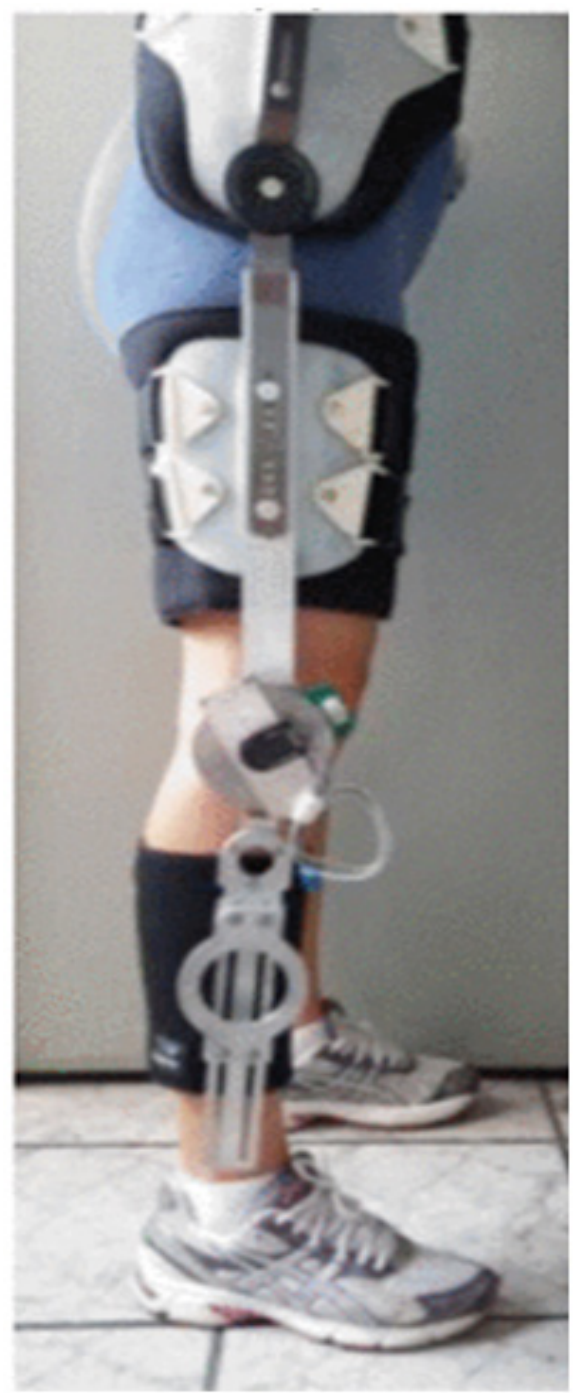

Figure 2: Pseudo-passive exoskeleton [9].

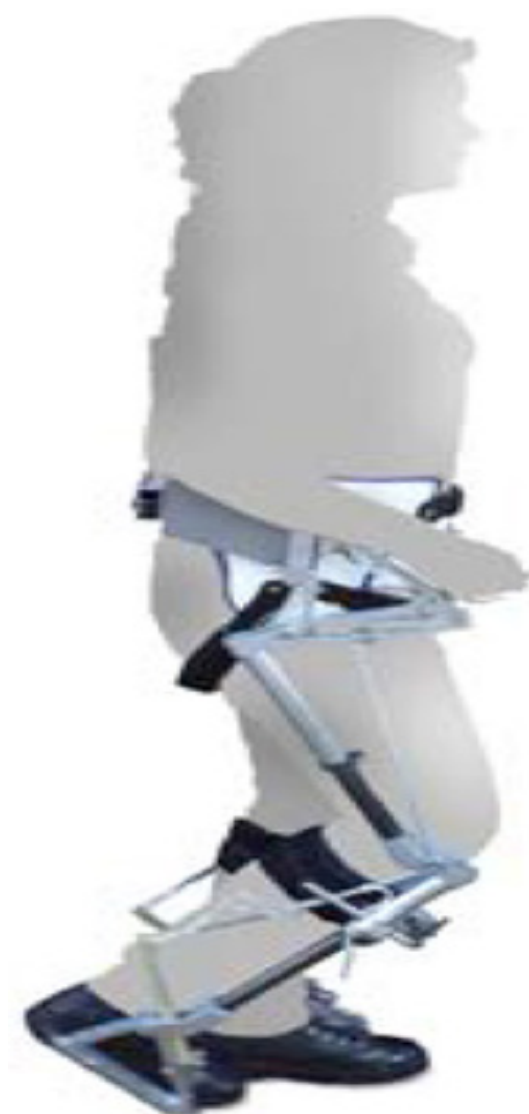

Figure 3: Passive exoskeleton [8].

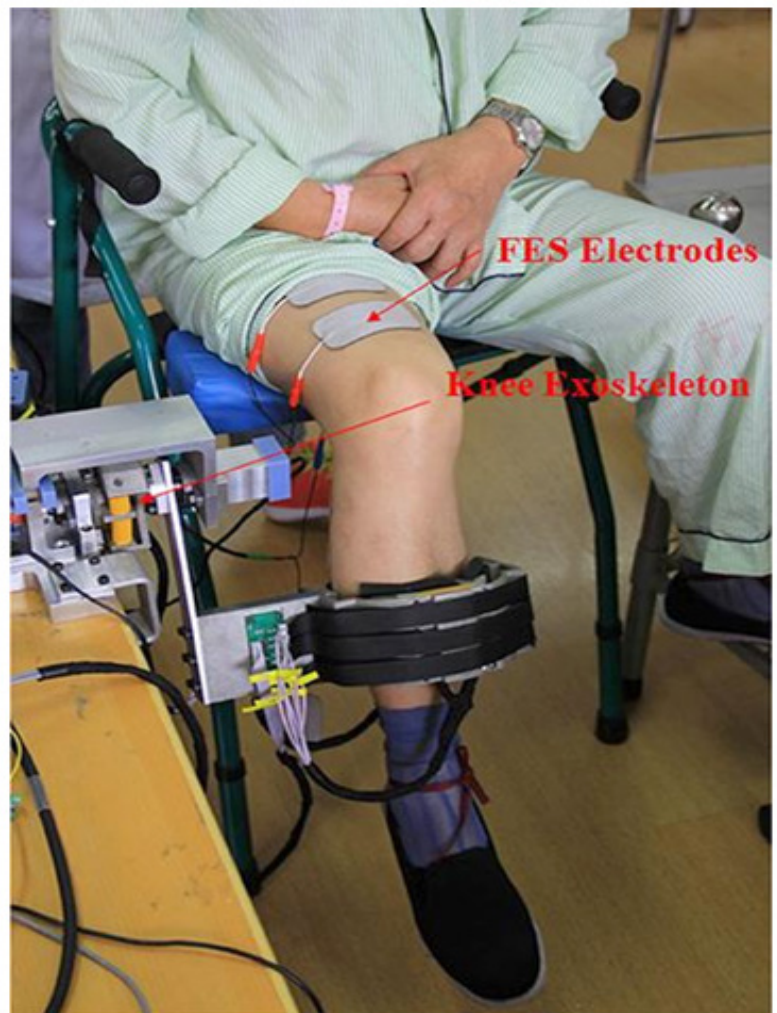

Figure 4: Hybrid exoskeleton [10]. 
Citation: Carnrike T, Egoh A, Reed KS, Kalu PN (2020) Bamboo Usage in Orthopedic: An Attempt to Reconcile Materials Properties with the Biomechanics of Human Walking. Int J Phys Ther Rehab 6: 164. doi: https://doi.org/10.15344/2455-7498/2020/164

Page 3 of 14

the current material (Duralumin), it is important that the cost of the new material must be significantly lower, in addition to maintaining the requisite properties for gait. Table 1 contains the cost and mass of the exoskeletons available in today's market [11-17].

An earlier study by Reed and Kalu, 2015, addressed the usage of natural materials for prosthetic and orthopedic devices in order to substantially reduce their cost [5]. Focusing on the loading requirements of the stance extremity, a comparison of all possible natural materials showed that bamboo with its excellent physical and mechanical properties can suitably replace Duralumin in exoskeleton design [5]. However, to fully consider the usage of bamboo for prosthetic and orthopedic device applications, a comprehensive assessment of the materials response to the external torque produced by the ground reaction force on the joint during the stance phase is necessary. To satisfy this requirement, the material must have high fracture toughness and formability.

\section{Kinetics and Kinematics of Walking}

\section{The gait cycle}

As shown in Figure 5, in a normal gait cycle the stance and swing phases consists of eight subunits or events [18]. The stance phase is labeled by the contact of the foot with the ground and involves five events, which include initial contact, loading response, mid-stance, terminal stance, and pre-swing. Although there are three basic tasks during gait: weight acceptance, single limb support and limb advancement. However, the specific tasks of weight bearing are carried out by the stance limb. The first $10 \%$ of the gait cycle corresponds to the task of weight acceptance at initial contact through loading response. The mid-stance, which occurs between $10 \%$ to $30 \%$ of the gait cycle is referred to as the single limb support and characterized by the body weight moving over to the forefoot $[18,19]$. The end of the weight acceptance, known as the terminal stance phase, is reached when the body weight moves anteriorly to the forefoot at $30 \%$ to $50 \%$ of the gait cycle. The last part of the gait cycle (60\% to $100 \%)$ is referred to as swing phase, and this has three events, namely: initial swing, mid-swing, and terminal swing. The swing phase is when the foot is not in contact with the ground and is primarily associated with limb advancement. A normal walking gait is dependent on these complex functional tasks being executed with precision.

In addition to all the aforementioned tasks, human locomotion involves the rotation of various joint segments to support, balance, control, and stabilize the body from excessive joint loads occurring during weight-bearing activity [18-20]. Furthermore, $10 \%$ of a person's total body weight is supported at mid-stance of the gait cycle [5]. Therefore, at a minimum, the exoskeleton must be able to endure/ support $10 \%$ of a person's total body weight. This translates to about $80 \mathrm{~N}$, since the average male weighs $80 \mathrm{~kg}$ (about $800 \mathrm{~N}$ ), the lower extremity exoskeleton must be able to withstand at least $80 \mathrm{~N}$ [5]. It is necessary to mention that this value can be less than the maximum ground reaction force obtainable, as discussed in later section.

\section{Ground Reaction Force}

Important to the mechanics of walking is the position of the vertical ground reaction force (vGRF) vector about the joint's axis [19-21]. The vGRF is used in clinical analysis of gait to represent the forces the body applies to the ground through the foot $[20,21]$. The force experienced by the ground is dependent on the acceleration of the body weight and is equal in magnitude and opposite in direction to the body weight acting upon it. Soon after initial contact, the progression of force application under the foot can exceed body weight. Since the COM is moving downwards and under some deceleration, a vGRF greater than body weight is needed to decelerate the downward movement of the body [22]. This could result in peak vGRFs that

\begin{tabular}{|l|l|l|}
\hline Name & Approximate Price & Mass $(\mathrm{kg})$ \\
\hline ReWalk by ReWalk Robotics & $\$ 77,000$ & 23 \\
\hline Indego by Parker Hannifin & $\$ 70,000$ & 12 \\
\hline Ekso GT by Ekso Bionics & $\$ 160,000$ & 20 \\
\hline REX by REX Bionics & $\$ 99,000$ & 38 \\
\hline Pheonix by SuitX & $\$ 30,000$ & 12.25 \\
\hline
\end{tabular}

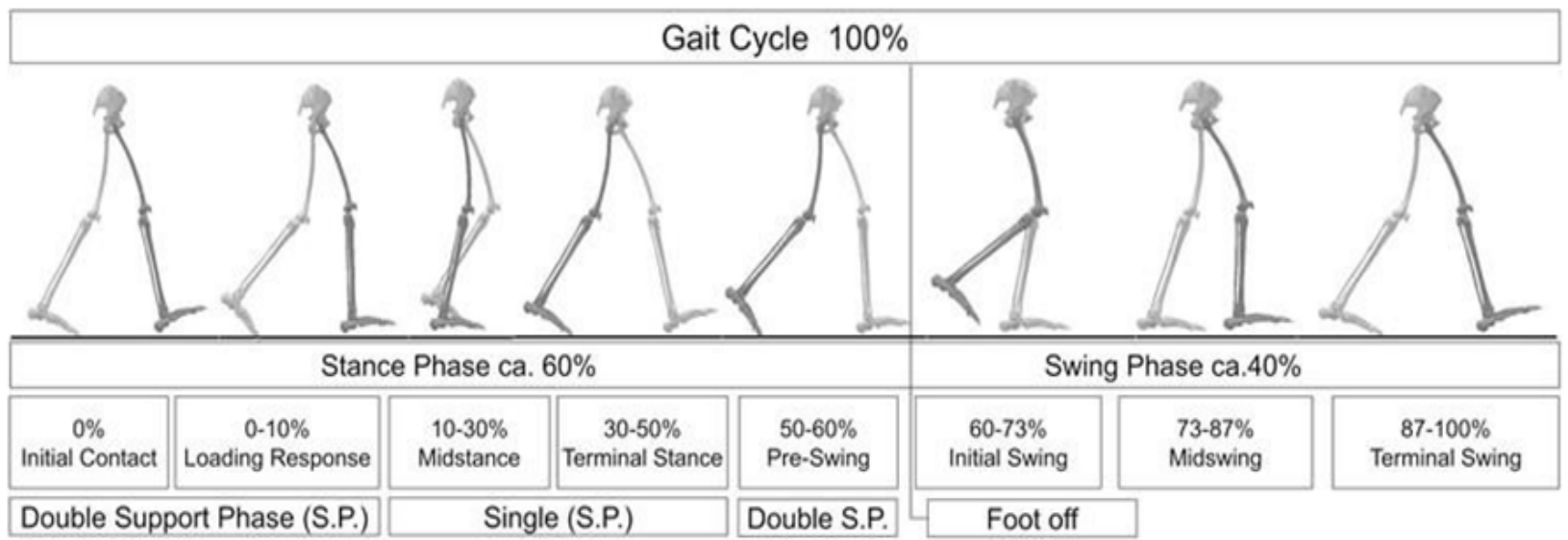

Figure 5: Phases and subunits of the Gait Cycle of Normal Walking [18]. 
Citation: Carnrike T, Egoh A, Reed KS, Kalu PN (2020) Bamboo Usage in Orthopedic: An Attempt to Reconcile Materials Properties with the Biomechanics of Human Walking. Int J Phys Ther Rehab 6: 164. doi: https://doi.org/10.15344/2455-7498/2020/164

Page 4 of 14

can reach up to 1.2 times the body weight (Figure 6) depending on the direction of the inertial force during the specific events of stance phase gait $[19,23]$. In fact, these reaction forces are nothing more than the algebraic summation of all body segments mass - acceleration products. The produced inertial force is added to the gravitational force and can be $100 \% \pm 20 \%$ of body weight transmitted to the foot forces needed to decelerate and accelerate the body forward [22]. Although fluctuations in inertial forces are highest at loading response and terminal stance, at mid stance, the vGRF is less than body weight resulting from the unweighting and upward momentum of body mass [19]. Since force is a function of mass and acceleration, the vertical acceleration can be up to $20 \%$ of gravitational acceleration upwards or downward [22]. To further understand the variations of the vGRFs around body weight, the gravitational, inertial and vGRFs likely contribution to different joint moments at the ankle, knee, and hip during normal gait should be discussed [24,25]. A wellresearched study by Boccardi, Pedotti, Rodano and Santambrogio (1981) analyzed the joint moments occurring at the hip, knee and ankle during stance phase to investigate the effects of the GRF on joint kinetics [26,27]. By utilizing Quasi-static calculations, the researchers concluded that inertial, gravitational, and GRF forces were highest at initial contact and pre-swing phases where the dynamic forces and accelerations of the body are greatest [25-27]. In addition, the study determined that gravity and inertial moments was greatest at the hip joints and relatively low at the ankle during slower walking speeds [27]. Since the extent of the GRF is subject to the foot's position as it contacts the ground, this is equally true for the center of gravity (COG) of the body. The center of gravity (COG) of a body is the net location of the body's center of mass in the vertical direction and is weighted average of the center of gravity of each body segment. The COG is reported to be 2 inches $(5 \mathrm{~cm})$ anterior to the second sacral vertebra [19]; and it is balanced and maintained by foot contact with the ground $[18,19]$. Although the sequences of motion patterns between the joints are constantly changing during walking, a change in the position of the foot or ankle could greatly challenge the body to provide support at each joint and generate propulsion [20,21]. As the foot becomes part of a closed kinetic chain at heel-strike, an alteration at the foot can result in proximal adaptations at the ankle, knee, hip, pelvis, spine, or the upper extremity to counterbalance the lower limb movement $[20,21,25,26]$. Conversely, the reactions of proximal joints to maintain COG can translate to a greater dependence on the proximal muscles of the pelvis, hip and knee joints to control stability and support the weight of the head, arms, and trunk (HAT) during lower limb loading [19]. Despite the fact that active rotary torques are common patterns of movement for many joints along the kinetic chain, the distance of the joint from the torso could likely determine the extent of rotation transpiring at each joint $[18,19]$. A change in foot position can alter the joints axis of rotation and cause different bending moments about the axis. This can lead to the influence of proximal muscle control on distal extremity kinematics and result in alterations in normal movement patterns essential to meet load and balance requirements at the hip and knee joints $[2,26]$. While a change in body alignment can influence the fluidity and efficiency of a walking gait, the determinants of the arms will respond to counter any excessive COG displacements $[18,19,25]$.

\section{The determinants of stance phase gait}

Pelvic rotation, pelvic tilt, knee flexion in stance phase, foot mechanics, knee mechanics, and lateral displacement of the pelvis are determinants of the gait cycle. These joint actions help to minimize COM excursions to maximize forward progression of the body with the least expenditure of energy [28]. Rotations of the major joints of the lower extremity limbs occur to progress the body forward while providing for weight-bearing support against external torques. Here, brief discussions of the major joint actions are necessary to provide a comprehensive appraisal of materials response. 1) Pelvic rotation: the pelvis rotates medially/anteriorly on swinging leg side. This action essentially lengthens that limb as it prepares to accept weight and help to keep limbs lengthened at lowest point of COM to prevent sudden



Figure 6: Vertical ground reaction forces (vGRFs) during the subphases of the stance phase during gait [23]. 
Citation: Carnrike T, Egoh A, Reed KS, Kalu PN (2020) Bamboo Usage in Orthopedic: An Attempt to Reconcile Materials Properties with the Biomechanics of Human Walking. Int J Phys Ther Rehab 6: 164. doi: https://doi.org/10.15344/2455-7498/2020/164

drop in COM; 2) Pelvic tilt: the pelvis on swing leg (opposite to weight bearing leg) is lowered 4-5 degrees where this action lowers the COM at mid stance; 3) Knee flexion in stance phase: knee flexes 15-20 degrees at initial contact and loading response. This action lowers the $\mathrm{COM}$ and reduces the otherwise high vertical elevation at mid stance to decrease energy expenditure. Also absorbs the shock of impact of heel strike mechanics; 4) Foot mechanics: The controlled plantar flexion at initial contact to smooth curve of the dropping pelvis; 5) Knee mechanics: the knee extends at mid-stance, and this action coincides with ankle plantarflexion and foot supination to restore length to leg; 6) Lateral displacement of pelvis: the pelvis is displaced towards the stance limb and muscle action helps to keep the COM above the base of support [28].

\section{Joint motions at initial contact period of gait}

When the heel contacts the ground at initial contact, the foot begins to decelerate, and weight is taken onto the stance limb. During this period, the foot assumes a position of slight dorsiflexion. It does this by bending and internally rotating at the hip and knee to slow foot movement and the abrupt drop of body weight from forces arising at heel-strike $[18,19]$. The summary of bodily movements will consist of a slightly flexed hip and medially rotated; the knee is slightly extended; the tibia is laterally rotated; the ankle is at $90^{\circ}$ with the foot supinated; and the hindfoot is everted $[18,19,26]$. As weight is taken onto the heel, the abrupt drop in body weight generates an immediate and transient GRF (Figure 7) between the foot and the ground. In order to maintain balance of the body as weight is taken onto the heel, rotation of the thorax occurs in the opposite direction of pelvic movement on the side of initial contact. The rotations at the pelvis provide counter-rotation forces between the swing and stance leg to decrease dips in the COG by lessening the angle of the femur with adjustments inlimb length $[19,20]$. As the trunk remains aligned between the two lower limbs [26], the GRF will be posterior to ankle and knee, and anterior to hip.

\section{Motions at loading response period of gait}

Load response follows the initial contact period of the foot's contact with the ground; identified by a progressive foot-flat neutral posture

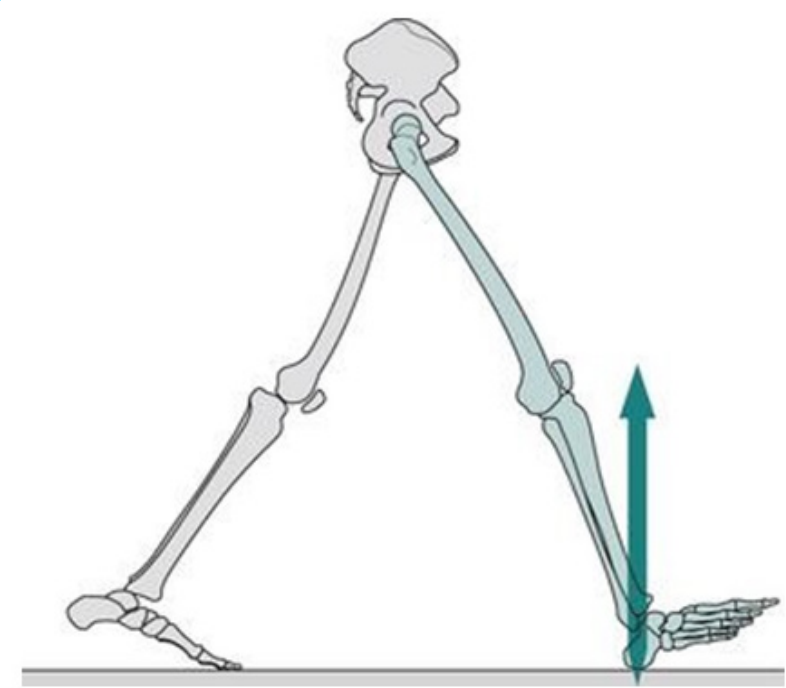

Figure 7: Sketch depicts the position of the right extremity and foot (light green) at initial contact and the corresponding transient ground reaction force vector (dark green) [18]. of the foot during the gait cycle. During this period of normal gait, the body weight is transferred onto the stance limb, and the trunk aligns with the stance leg for stability $[18,19]$. The summary of bodily movements consists of advancing hip extension, the knee is slightly flexed, and the tibia begins to advance forward to move bodyweight over the fixed foot. As the body progresses over the foot, the ankle is plantar flexed, and the hind-foot inverts so the foot can move into a position of pronation [19]. This allows mobility and adaptation to different ground surfaces and postures of the body for effective shock absorption. Here, the forces will be slightly higher than body weight. The vGRF is aligned posterior to the ankle and knee, and anterior to the hip. See Figure 8.

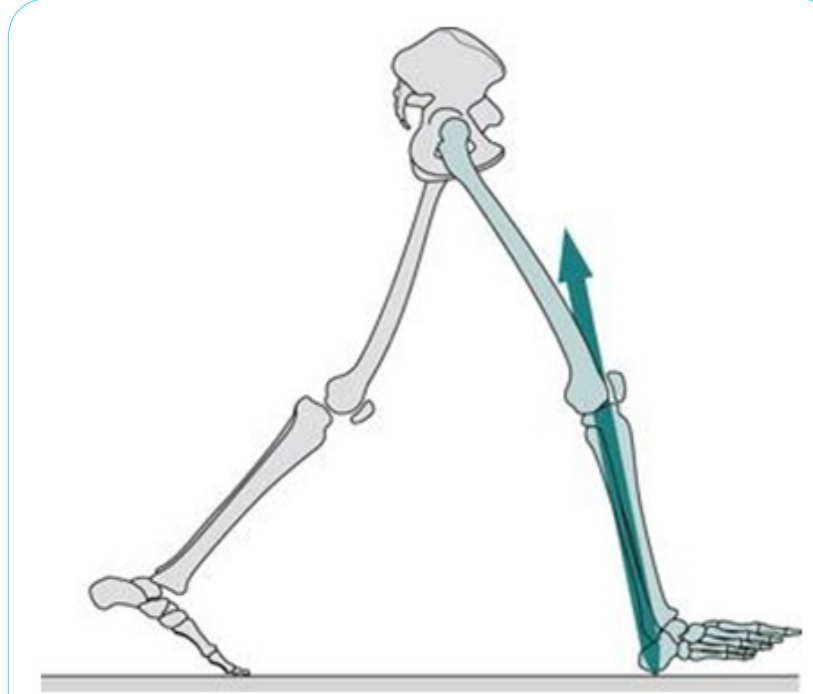

Figure 8: Illustration depicts the position of the extremity during loading response (light green) and the corresponding ground reaction force vector (dark green) after initial contact [18].

\section{Joint motions at mid stance period of gait}

The Mid stance period is a period when full body weight is taken onto the stance limb. During this period of fixed foot support, the

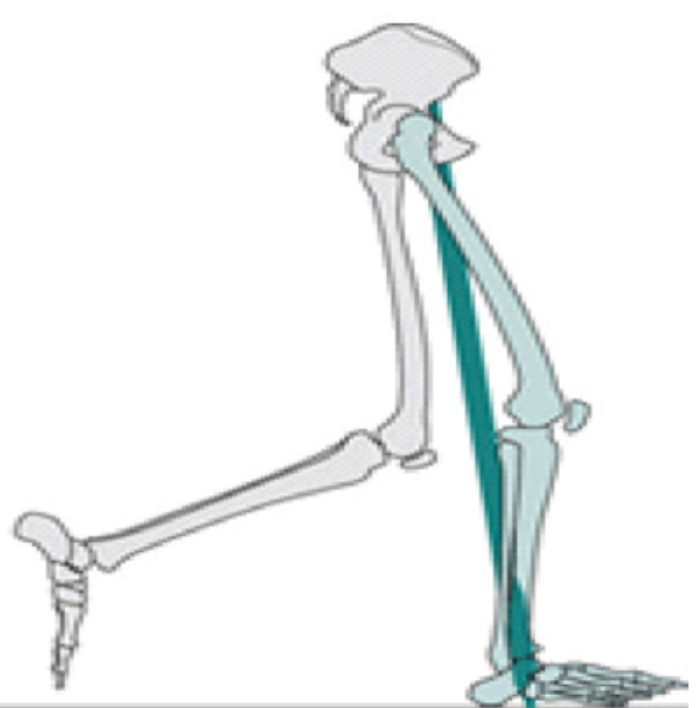

Figure 9: Depicts the mid stance period during lower extremity loading (light green), and the location of the ground reaction force (dark green) acting on the extended knee [18]. 
Citation: Carnrike T, Egoh A, Reed KS, Kalu PN (2020) Bamboo Usage in Orthopedic: An Attempt to Reconcile Materials Properties with the Biomechanics of Human Walking. Int J Phys Ther Rehab 6: 164. doi: https://doi.org/10.15344/2455-7498/2020/164

Page 6 of 14

hip and knee has stopped rotating inwards and is now straight to contribute to the stability of the whole body for an upright standing position $[18,19]$. Additionally, COG is highest at mid stance. The summary of bodily movements consists of maximum extension and external rotation at the hip; the knee is locked in extension with the heel and forefoot in contact with the ground. During this period from liftoff of opposite leg to point where ankles of legs align in the frontal plane, the forefoot is pronated and hindfoot is inverted for even weight distribution across the entire foot [19]. The weight bearing capacity of the body as a whole is dependent on alignment of the three lower-extremity joints-hip, knee, and ankle. The vGRF vector is close to going through most joints, where it moves from behind the ankle joint axis to an anterior alignment of the ankle axis to balance and stabilize the gravitational effects acting on the body (Figure 9). During single-limb support, the vGRF will be less than body weight. Here, the downward acceleration of the COM and the upward inertial force act to reduce the GRF to $85 \%$ of body weight $[18,22]$.

\section{Joint motions at terminal stance period of gait}

During the period of terminal stance, bodyweight moves forward on the foot so that only the big toe is in contact with the ground. In this instance of a heel off position, the stance extremity is unloading bodyweight to the contralateral limb to progress to the swing phase of gait $[18,19]$. As the trunk moves toward the supporting leg, the pelvis drops to the swing limb side but maintains a posteriorly rotated position to counter rotational forces between the swing and stance leg. The knee is in a position of extension, tibia externally rotated, ankle plantar flexed, and the heel assumes a neutral and slightly internally rotated position to drive movement of the body forward [19]. The continued advancement of the pelvis and lower extremity progress the tibia anteriorly to cause the heel to rise. Jointly, these actions help to smooth the pathway of the center of gravity. Here, the vGRF is located anterior to the ankle joint and progresses posterior to knee and hip joint to reverse the downward movement of the body (Figure 10). The vGRF will be higher than body weight at terminal stance associated to the combined push provided by the plantar flexors occurring through pre-swig.

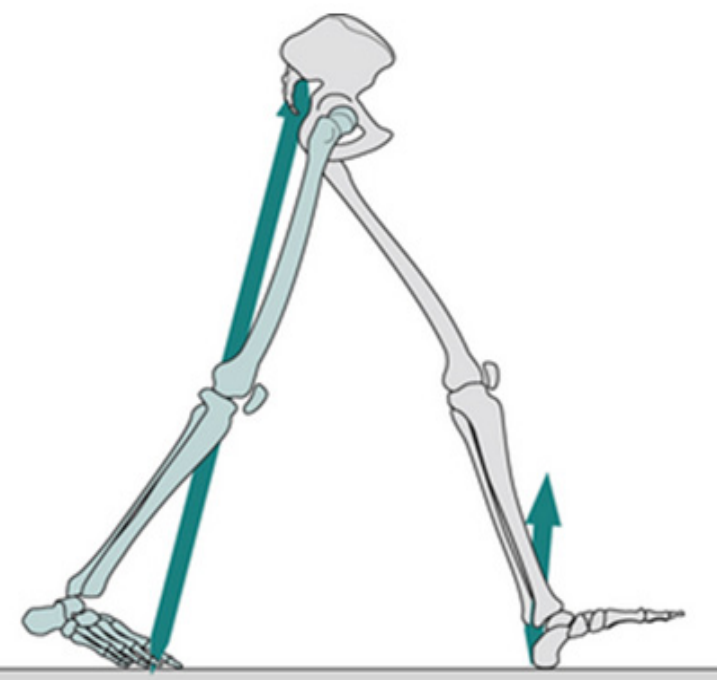

Figure 10: Illustrates the position of the leg at terminal stance of the gait cycle. The position of the stance lower extremity (light green) and the location of the resultant ground reaction force (dark green) at heel-off [18].

\section{Joint motions at pre-swing period of gait}

The pre-swing phase is the toe off acceleration phase. From initial contact of the opposite leg to just prior to lift off, body weight is transferred to the swing leg as the toe pushes the leg forward to accelerate mass [19]. The trunk remains erect, the pelvis remains posteriorly rotated, and the hip is extended and slightly medially rotated. The knee flexes slightly, and the ankle is plantar flexed on the ground to generate momentum in order to push the leg forward and accelerate the hip forward in initial swing [18].

As shown in Figure 11, the GRF is located anterior to the ankle and posterior to the knee and hip joint during pre-swing. The active plantar flexors cause a second peak force greater than body weight as a result of the body's center of mass is being accelerated upwards to increase its upward velocity.

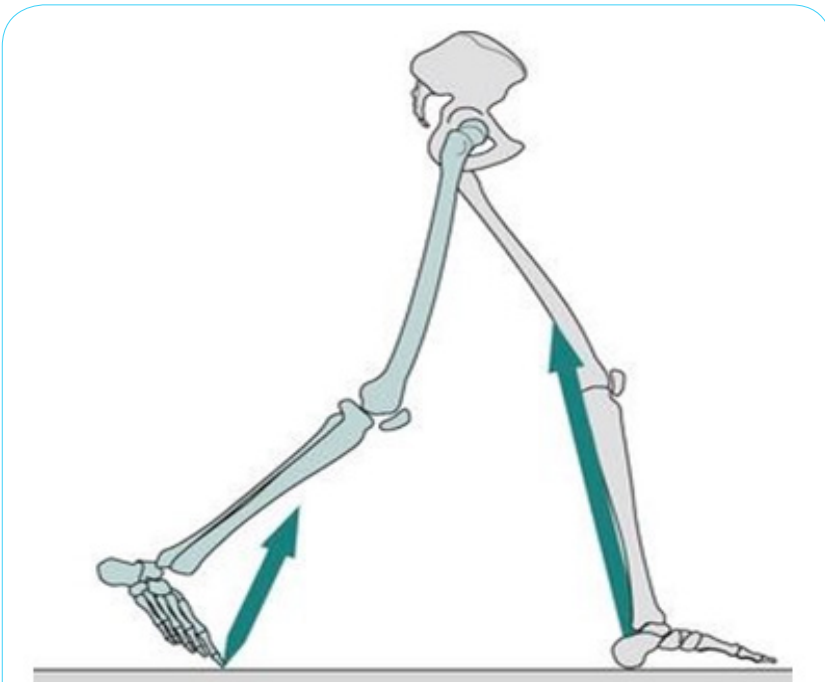

Figure 11: Illustrates the position of the leg at terminal stance of the gait cycle. The position of the stance lower extremity (light green) and the location of the resultant ground reaction force (dark green) at heel-off [18].

\section{Materials and Methods}

The material selection process used in this study is fashioned according to the Ashby's procedure and consists of four steps, namely: translation, screening, ranking, and documentation [29]. Translation involves breaking down the design requirements into functions, constraints, objectives and free variables. In the screening step, nonnegotiable constraints are imposed on the materials and this result in the elimination of materials that cannot do the job. Ranking requires the use of material indices to indicate how well the screened materials perform the tasks based on specified properties. Finally, the documentation step investigates the materials selected in the ranking stage in order to choose the most compatible one. The details of the Screening and Ranking are similar to that reported in the previous study [5] and are provided below.

\section{Results and Discussion}

\section{Translation}

In this step, the requirements for an exoskeleton and prosthetic design are translated into basic models for proper analysis. The 
Citation: Carnrike T, Egoh A, Reed KS, Kalu PN (2020) Bamboo Usage in Orthopedic: An Attempt to Reconcile Materials Properties with the Biomechanics of Human Walking. Int J Phys Ther Rehab 6: 164. doi: https://doi.org/10.15344/2455-7498/2020/164

Page 7 of 14

design requirements for an exoskeleton and prosthetic are given in the Function-Constraints-Objectives-Free Variables (FCOFV) chart of Table A-1 [5]. In addition to the preliminary FCOFV components, additional requirements such as high fracture toughness and reasonable formability were added in order for the material to accommodate the joint torques generated from ground reaction forces during walking.

\begin{tabular}{|l|l|}
\hline Function & Beam or Column \\
\hline \multirow{4}{*}{ Constraints } & -Length L specified \\
\cline { 2 - 2 } & -Strength: must not fail under design loads \\
\cline { 2 - 2 } & -Buckling: must not buckle under design loads \\
\cline { 2 - 2 } & -Must not fracture if accidently struck \\
\cline { 2 - 2 } & -Must support at least 10\% of a person's total weight \\
\hline \multirow{2}{*}{ Objectives } & Minimize cost, C \\
\hline Free Variables & -Diameter of column \\
\cline { 2 - 2 } & -Choice of material \\
\hline \multirow{2}{*}{$\begin{array}{l}\text { Additional } \\
\text { Requirements }\end{array}$} & -High fracture toughness \\
\cline { 2 - 2 } & -Reasonable formability \\
\hline
\end{tabular}

Table A-1: Design Requirements for an Exoskeleton.

\section{Screening}

Screening consists of eliminating the materials that do not satisfy the basic needs; in this case the basic need is low density. Orthopedic and prosthetic devices available in the market are typically made out of Duralumin but Carbon Fiber Reinforced Polymer (CFRP), and steel (AISI 4130) have also been considered. The properties of Duralumin (Al-2024 T6), CFRP (longitudinal), and AISI 4130 steel are shown in
Table B-1[30-34]. Duralumin is typically used for exoskeletons as it is well defined, already used in a variety of applications such as airplanes, and has a low density compared to that of steel and low cost compared to carbon fiber. The new material must be able to support up to 1.2 times the body weight as detailed in the section on the Kinetics of Walking. This suggests that the strength and stiffness properties of Duralumin may be an overkill in the current design of exoskeletons. The additional requirement for the material to absorb the joint torques generated from ground reaction forces during walking necessitate the evaluation the density, fracture toughness and formability of the material. With these parameters in mind, the strength versus density chart was plotted as shown in Figure A-1 to narrow down the suitable

\begin{tabular}{|l|l|l|l|}
\hline Properties & Duralumin & $\begin{array}{l}\text { CFRP } \\
\text { (longitudinal) }\end{array}$ & $\begin{array}{l}\text { AISI } 4130 \\
\text { Steel }\end{array}$ \\
\hline Density $\left(\mathrm{g} / \mathrm{cm}^{3}\right)$ & 2.77 & 1.60 & 7.85 \\
\hline Vickers Hardness & 142 & - & 207 \\
\hline Yield Strength (MPa) & 345 & - & 435 \\
\hline $\begin{array}{l}\text { Ultimate Strength } \\
(\mathrm{MPa})\end{array}$ & 427 & $1,100-1,900$ & 670 \\
\hline $\begin{array}{l}\text { Modulus of Elasticity } \\
(\mathrm{GPa})\end{array}$ & 72.4 & $120-140$ & 205 \\
\hline $\begin{array}{l}\text { Modulus of } \\
\left.\text { Resilience (kJ/m }{ }^{3}\right)\end{array}$ & 980 & - & - \\
\hline $\begin{array}{l}\text { Izod Impact Strength } \\
(\mathrm{J} / \mathrm{m})\end{array}$ & $8-22$ & - & - \\
\hline $\begin{array}{l}\text { Current Cost per kg } \\
\text { (\$/kg) }\end{array}$ & 4.46 & $40-44$ & $0.9-1.82$ \\
\hline $\begin{array}{l}\text { Table B-1: Properties of Duralumin (Al-2024 T6), CFRP (longitudinal), } \\
\text { and AISI 4130 steel. }\end{array}$ & \multicolumn{3}{|l}{} \\
\hline
\end{tabular}

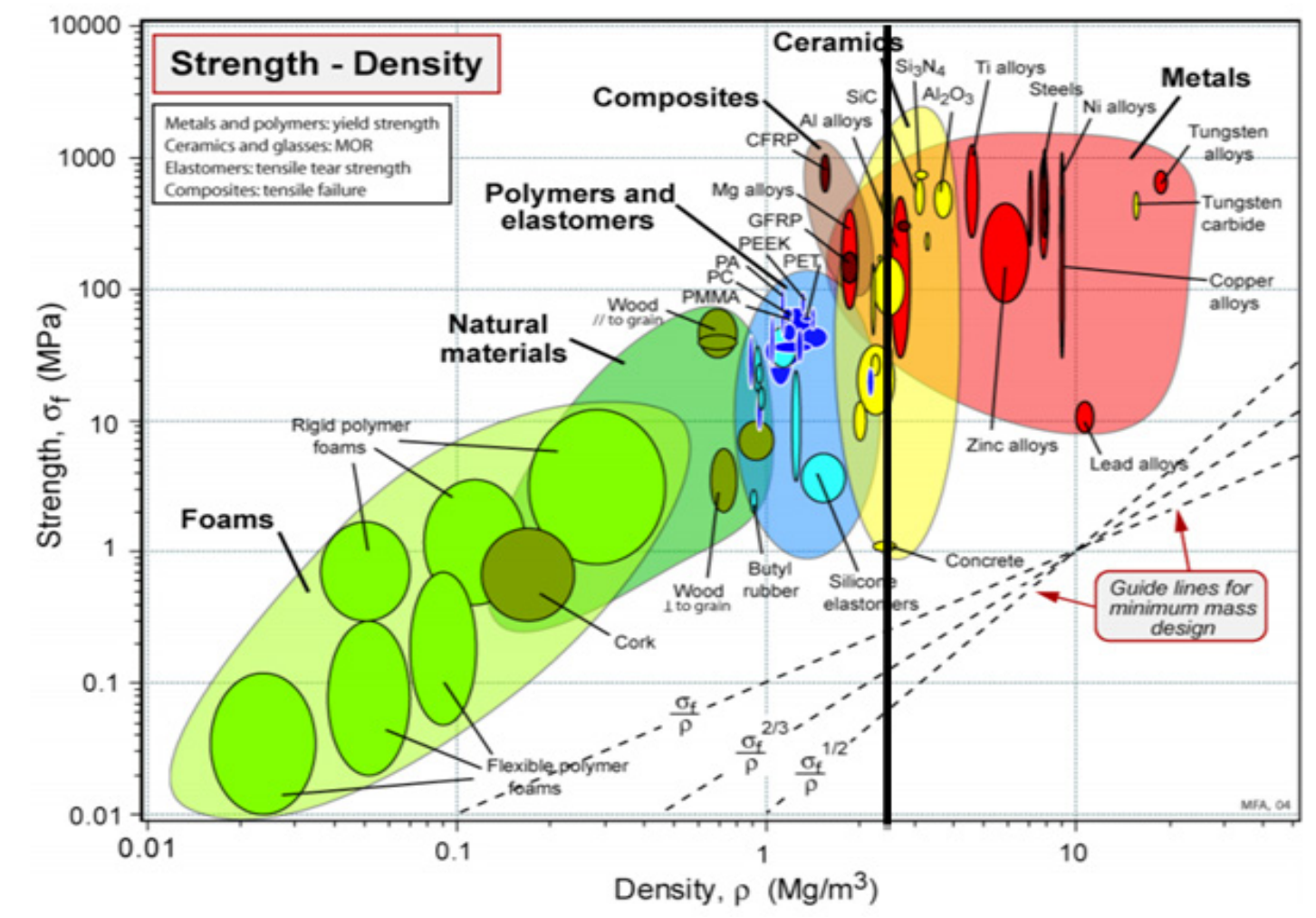

Figure A-1: Strength vs Density Chart (Chart created using CES EduPack, Granta Design Ltd). 
Citation: Carnrike T, Egoh A, Reed KS, Kalu PN (2020) Bamboo Usage in Orthopedic: An Attempt to Reconcile Materials Properties with the Biomechanics of Human Walking. Int J Phys Ther Rehab 6: 164. doi: https://doi.org/10.15344/2455-7498/2020/164

material classes [29]. Using Figure A-1 as a reference, it is clear that some metals, ceramics, composites, polymers and elastomers, natural materials, foams all meet the density requirement. In other words, these materials lie to the left of the vertical line which is situated at the density of Duralumin.

\section{Ranking}

All the materials that passed the screening step were then ranked, using material indices, based on how they fared when the constraints of weight, strength and cost, were applied. The exoskeleton and prosthetic devices were modeled using material indices for an inexpensive beam with prescribed strength, using Equation 1 [29].

$$
M_{1}=\frac{\sigma_{y}^{2 / 3}}{C_{m} \rho}
$$

In addition to an inexpensive beam with prescribed strength, the exoskeleton and prosthetic devices were also modeled as an inexpensive column with prescribed buckling load, as shown in Equation 2 [29].

$$
M_{2}=\frac{E^{1 / 2}}{C_{m} \rho}
$$

In these equations, $M$ is the material indices, $\sigma_{y}$ is the yield strength, $C_{m}$ is the cost per $\mathrm{kg}, \rho$ is the materials density, and $E$ is the Modulus of Elasticity. Figure A-2 addresses an inexpensive beam with prescribed strength [29]. By maximizing the material indices (Equation 1) in Figure A-2, represented by the bold line, the best material candidates are natural materials, and some metals and nontechnical ceramics. The materials are located above the bold line to the left of the chart. It is important to notice that this eliminates some of the materials found in the screening stage such as polymers and elastomers, foams, and composites (below the bold line). Figure A-3 addresses an inexpensive column with prescribed buckling load [29]. Maximizing the material indices in Equation 2, using the bold line, it is clear that natural materials, nontechnical ceramics, some technical ceramics, and some metals (above the bold line)) meet this requirement. Taking into account the material candidates from the screening stage as well as from Figures A-2 and A-3, the best material classes for this application is the natural materials, some metals, and some nontechnical ceramics. These set of materials are inexpensive and provide sufficient properties, based on the material indices, for the application.

\section{Documentation: Assessment of Materials}

Having established that natural materials, nontechnical ceramics, and metals are best suited from the ranking step, it is therefore necessary to document these materials. There are a variety of natural materials, but the most commonly used in everyday application include fir, pine, oak, and bamboo. Figure 12 compares the Young's modulus and yield strength for the natural materials stated above as well as Duralumin [5]. The bamboo considered in this plot is Moso Bamboo (phyllostachys edulis) as it is one of the most common, well defined, and strong bamboo species. Although nontechnical ceramics are not included in the plot, if they were, they would be located near bamboo. Figure 12 shows that besides Duralumin (Al2024 T6), Moso bamboo exhibits superior properties compared to the other natural materials. Figure 13 shows a density versus price graph for various materials including Fir, Pine, Oak, Moso bamboo, Duralumin, and Nontechnical Ceramics. The natural materials clearly show dominance in Figure 13 as they have the lowest density and cost.

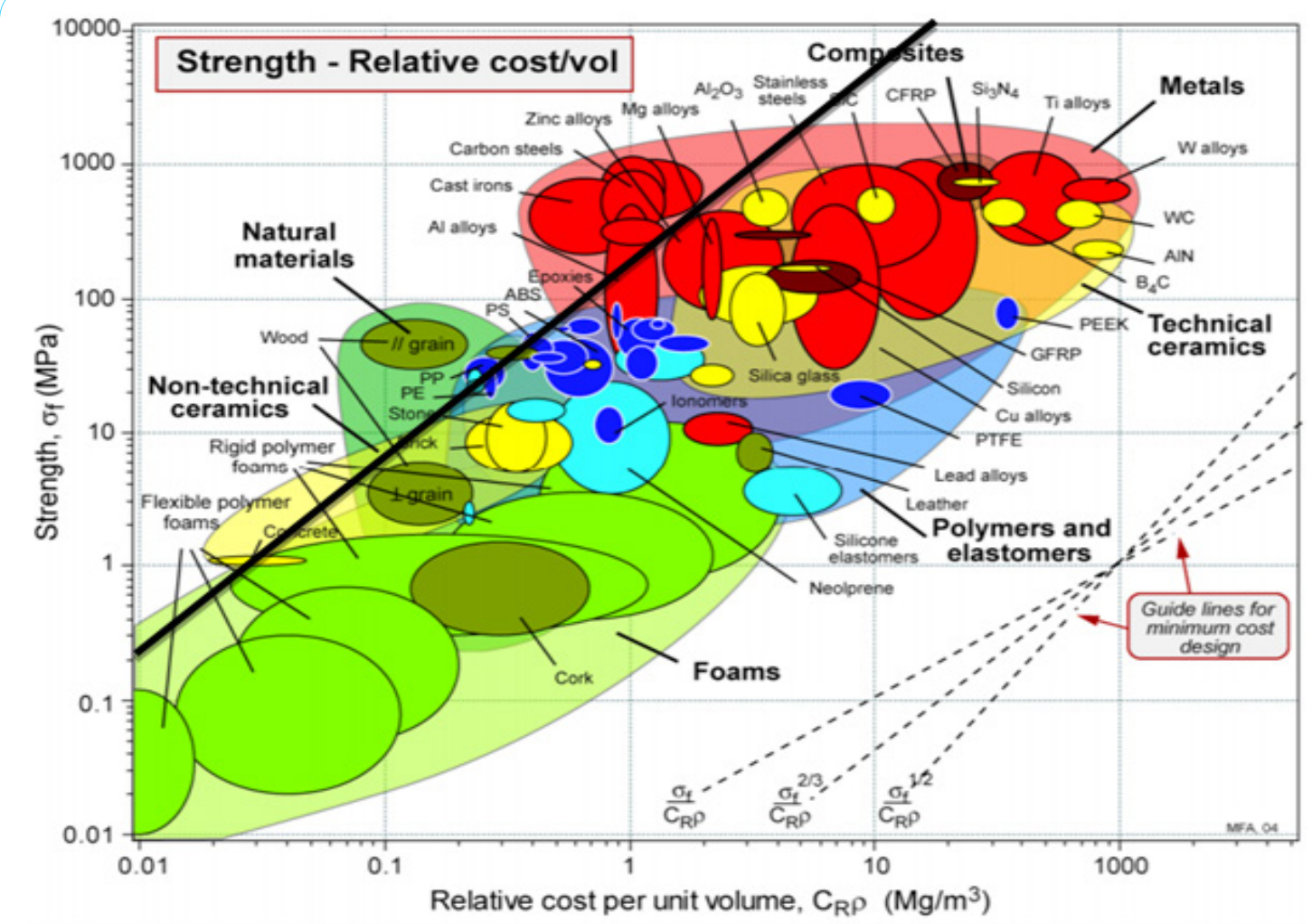

Figure A-2: Strength vs relative cost per unit volume (Chart created using CES EduPack, Granta Design Ltd). 
Citation: Carnrike T, Egoh A, Reed KS, Kalu PN (2020) Bamboo Usage in Orthopedic: An Attempt to Reconcile Materials Properties with the Biomechanics of Human Walking. Int J Phys Ther Rehab 6: 164. doi: https://doi.org/10.15344/2455-7498/2020/164

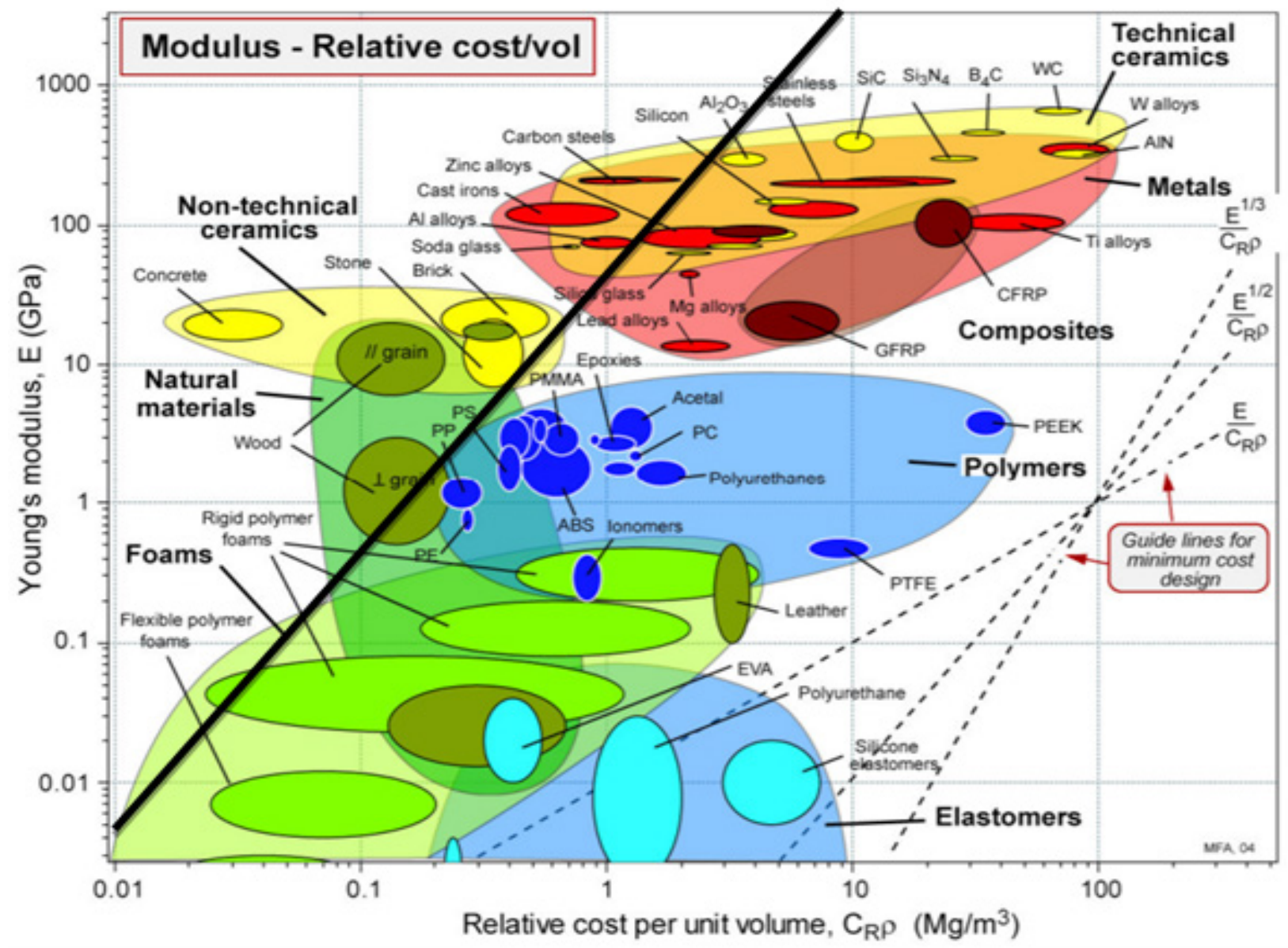

Figure A-3: Young's modulus vs relative cost per unit volume (Chart created using CES EduPack, Granta Design Ltd).

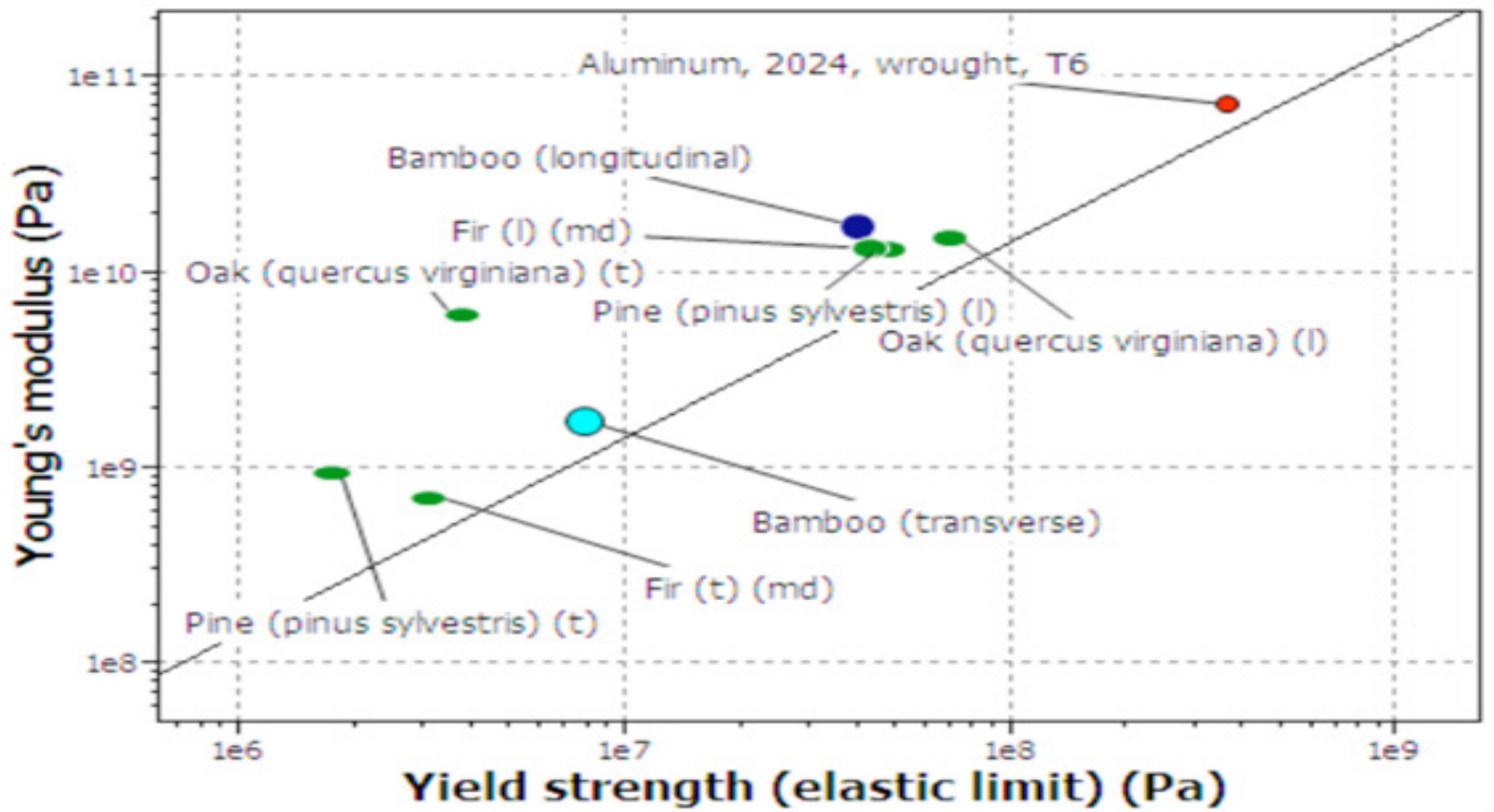

Figure 12: Young's modulus vs yield strength comparison between Duralumin and the four natural materials. 
Citation: Carnrike T, Egoh A, Reed KS, Kalu PN (2020) Bamboo Usage in Orthopedic: An Attempt to Reconcile Materials Properties with the Biomechanics of Human Walking. Int J Phys Ther Rehab 6: 164. doi: https://doi.org/10.15344/2455-7498/2020/164

Although Moso bamboo is not as light as Fir, Pine, and Oak, it is the least expensive natural material discussed.

The mechanical properties of the various materials under consideration are shown in Table 2.

In Table 2, yellow represents the baseline which in this case is the Duralumin and green represents the properties superior in each category. When considering the application, it is very important to consider the compressive strength of materials especially in the case of muscle deficiency. More specifically, if a person lacks the muscle to absorb some of the reaction force, then the material being used must be able to withstand the entire reaction force not just the amount typically absorbed by the muscle. It has been found that during normal walking the vertical peak ground reaction force can reach 1.2 times the bodyweight in extreme cases [23]. The average body weight of a male is $80 \mathrm{~kg}$ which converts to about an $800 \mathrm{~N}$ force. In the case explained above, in which the extreme reaction force is 1.2 times the bodyweight, the reaction force would be $960 \mathrm{~N}$. To withstand this reaction force, the cross-sectional area in which the force is applied was analyzed. Besides Duralumin, which is considered overkill, the Moso Bamboo requires the smallest area to accommodate the reaction force, as it has the largest compressive strength. Although the Duralumin meets the requirements in terms of materials properties, it is considered overkill because it's density and cost are high in comparison with Moso Bamboo. This being said, the orthopedic device would not need to be bulky to sustain the forces of normal walking, as less surface area is needed.

\section{Fracture toughness of materials}

In addition to the Young's modulus and yield strength, it is important to pay attention to the fracture toughness, as this is what dictates how much a material can take before a preexisting flaw causes failure. This property is very important because in many cases, such as single limb stance during normal walking, the device, if used for the supporting limb, must be able to support the balancing of the weight of the head, arms, and trunk. More specifically, devices such as the exoskeleton must be able to stabilize the lower extremity by using the external moments generated by the GRF to apply external moments at

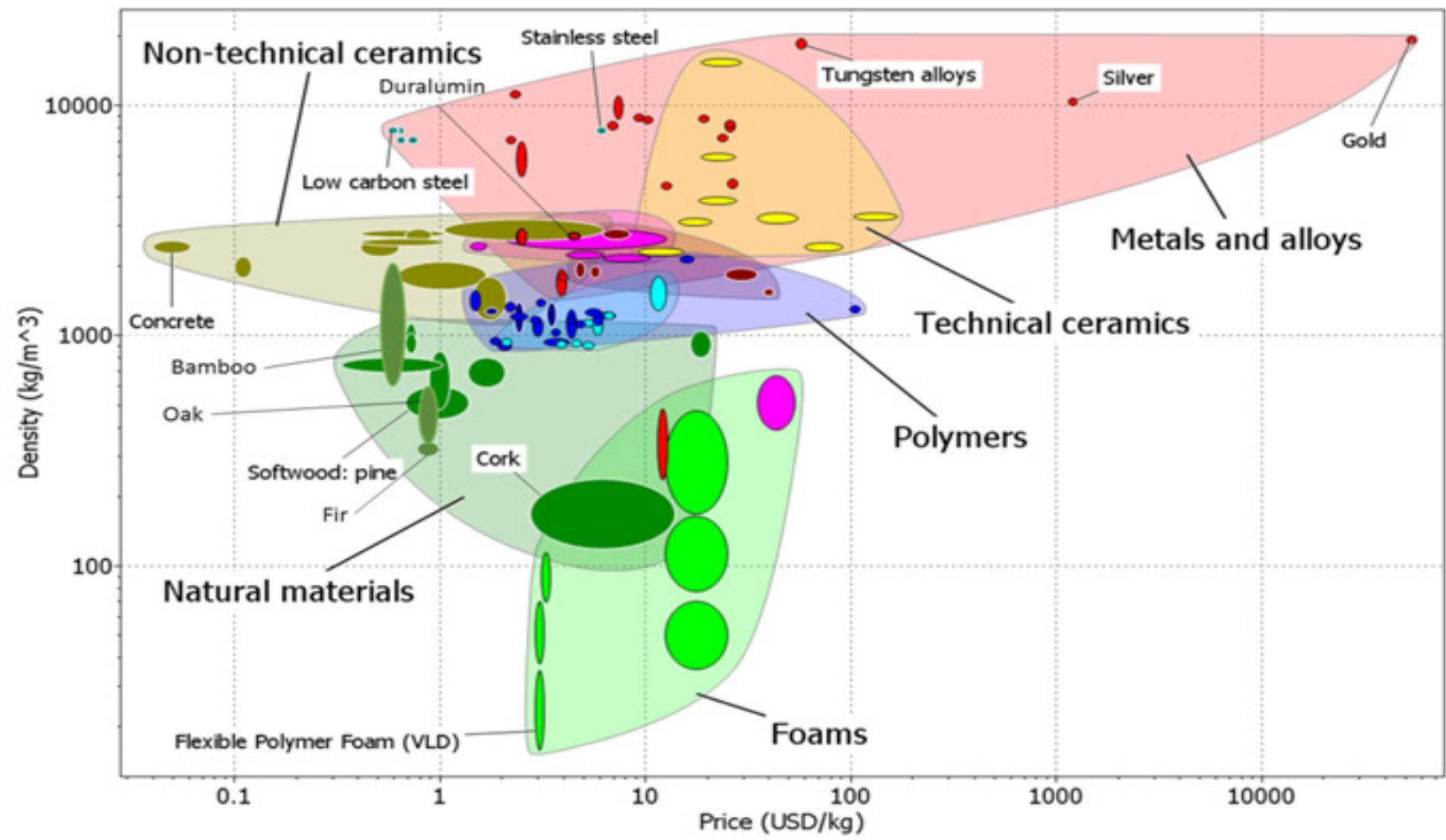

Figure 13: Density vs Price for various materials (Chart created using CES EduPack, Granta Design Ltd).

\begin{tabular}{|c|c|c|c|c|c|c|c|}
\hline Material & Density $\left(\mathrm{g} / \mathrm{cm}^{3}\right)$ & $\begin{array}{l}\text { Young's } \\
\text { Modulus (GPa) }\end{array}$ & $\begin{array}{l}\text { Tensile } \\
\text { Strength }(\mathrm{MPa})\end{array}$ & $\begin{array}{l}\text { Compressive } \\
\text { Strength (MPa) }\end{array}$ & $\begin{array}{l}\text { Cost per kg } \\
(\$ / \mathrm{kg})\end{array}$ & $\begin{array}{l}\text { Fracture } \\
\text { Toughness } \mathrm{K}_{1 \mathrm{C}} \\
\left(\mathrm{Mpa}^{*} \mathrm{~m}^{1 / 2}\right)\end{array}$ & Reference \\
\hline Fir & $0.31-0.34$ & $5.9-6.7$ & $30.7-33.8$ & 49.9 & $0.8-1$ & 1.64 & 37 \\
\hline Pine & $0.35-0.42$ & $6.5-8.8$ & $34.0-41.6$ & 33.1 & $0.8-1$ & 0.40 & 37 \\
\hline Oak & $0.53-0.61$ & $7.9-12.4$ & $47.7-74.9$ & 46.6 & $0.8-1$ & 0.55 & 36 \\
\hline Moso bamboo & $0.55-1.0$ & $9-27.4$ & $111.5-309.3$ & 69.1 & 0.5 & 56.8 & $37-39$ \\
\hline Duralumin & 2.77 & 72.4 & 345 & 303 & 4.46 & $\sim 30$ & $30-31$ \\
\hline Nontechnical ceramics & $1.90-3$ & $15-60$ & $32-248$ & - & $0.4-1.7$ & 0.35 & 29 \\
\hline
\end{tabular}

Table 2: Properties of the selected materials [5]. 
Citation: Carnrike T, Egoh A, Reed KS, Kalu PN (2020) Bamboo Usage in Orthopedic: An Attempt to Reconcile Materials Properties with the Biomechanics of Human Walking. Int J Phys Ther Rehab 6: 164. doi: https://doi.org/10.15344/2455-7498/2020/164

Page 11 of 14

the knee and hip so the passive structures at these joints can provide support to keep the center of mass (COM) over the base of support. In order to maintain this stability, the material being used must possess high fracture toughness to avoid any flaw propagation which could cause the person to become unstable during normal walking [35,36]. Fracture toughness can be related to the yield strength, as shown in Equation 3, when considering the process zone, a plastic zone [30]. The process zone is generated by a stress concentration at the tip of the crack. For composites (natural materials being considered natural composites), the plastic zone is one of debonding, delamination, and fiber pull out [29].

$$
K_{1 c}=\sigma Y \sqrt{\pi d_{y}}
$$

Figure 14 shows the fracture toughness versus yield strength for the natural materials, Duralumin (metal), and nontechnical ceramics.

Although Duralumin has a higher yield strength than bamboo, bamboo's fracture toughness is higher. Compared to the other natural materials and nontechnical ceramics, bamboos fracture toughness and yield strength is far superior. The high fracture toughness of bamboos means that bamboo has a higher ability to resist fracture when a crack is present. Thus, if the ground reaction force (GRF) causes a crack in the exoskeleton, the amount of stress needed to propagate this crack is higher in bamboo compared to the other materials in Figure 14. Table 2 displays some properties of the four natural materials, nontechnical ceramics, as well as for Duralumin, which is considered the baseline as it is the current material used in exoskeletons. Natural materials are anisotropic and absorbent, thus their properties vary based on direction and moisture content, contributing to the variance in values shown in Table 2 [29-31,37-39].

\section{Formability of materials}

In addition to fracture toughness, it is important to consider the formability of each material. The material must possess reasonable formability as the construction of orthopedic devices, such as exoskeletons, require complex forming of various shapes. Formability is the ability of a material to undergo permanent deformation without being damaged. Nontechnical ceramics do not possess reasonable formability characteristics due to their brittle nature thus they were not considered. Bending natural materials into their desired shape is considered a measure of formability. Wei and company investigated the bending flexibility of Moso bamboo using two types of loading/ orientation, based on the arrow shape of the fibers [40]. These arrows shaped fibers point towards the inside of the bamboo culm [40]. The two loading types are when the arrow shape is pointing upwards (Type I) and pointing downwards (Type II) [40]. This study found that the notable bending characteristics of Moso bamboo is due to the "graded distribution and gradient variation of cell size of tougher fibers embedded in weaker parenchyma cells along the thickness of bamboo culm" [40].

There are three main bending techniques used for natural materials: laminating, heating, and kerfing [41]. Laminating is the least laborintensive process involving gluing strips of natural material together [41]. Heating encompasses a variety of processes but the most common one being steam bending, in which the wood is put in a steam box to soften $[41,42]$. The heating process is the lengthiest process but produces flexible and stronger curves [41,42]. Kerfing, the last of the three bending processes, involves cutting a series of slits into the wood to allow bending [41]. Although kerfing is the quickest approach, it leaves the wood in a much weaker condition [41]. Bending with heat is the best method to form natural materials into their desired bent shape, as it does not weaken the material drastically and avoids altering the state of the material. Bending with heat is typically used on hardwood materials, such as bamboo and oak, as they possess high bending quality, whereas softwoods, such as fir and pine, possess low bending quality [43]. Oak can be bent with the steam bending process whereas bamboo is bent using a heat source such as a torch [44]. Figure 15 shows bamboo used in furniture after it has undergone the heat bending process [45].

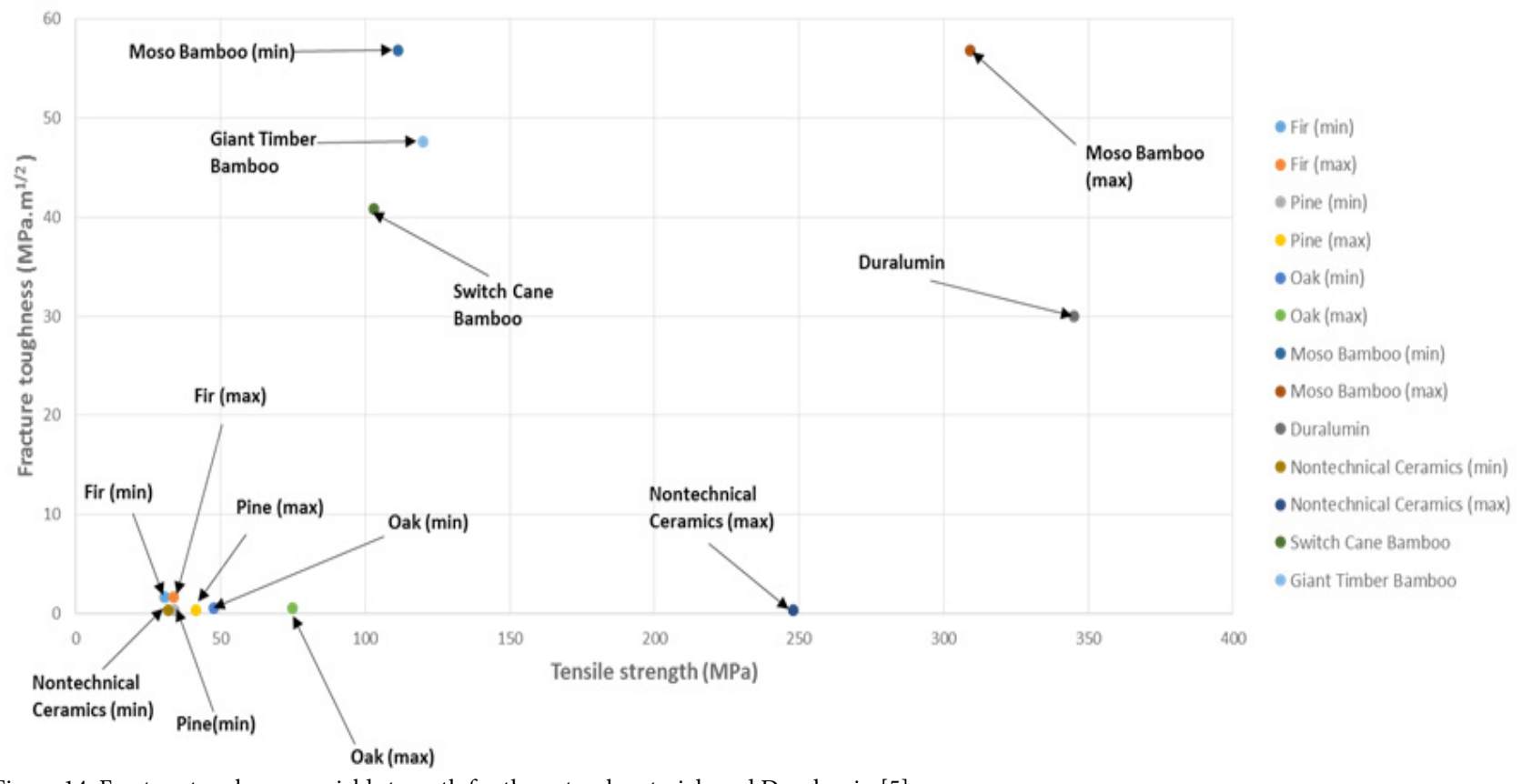

Figure 14: Fracture toughness vs yield strength for the natural materials and Duralumin [5]. 
Citation: Carnrike T, Egoh A, Reed KS, Kalu PN (2020) Bamboo Usage in Orthopedic: An Attempt to Reconcile Materials Properties with the Biomechanics of Human Walking. Int J Phys Ther Rehab 6: 164. doi: https://doi.org/10.15344/2455-7498/2020/164

Page 12 of 14

Although all the natural materials investigated are capable of performing the required function while maintaining their rigidity, bamboo and oak are the only materials investigated with reasonable formability but bamboo is considered the best candidate for the exoskeleton and prosthetic application as its fracture toughness, strength, and cost exceed that of oak.

\section{Assessment of some Indigenous Bamboos in the United States}

There are over 1,000 species of bamboo and each of these species has their own set of properties. Within each species, their properties change based on many factors, some of which are moisture content, loading direction, state (culm, sectioned or fiber), age, and height.

The properties considered are based on the bamboo species in their culm state as well as axial measurement. Moisture content is one of the most common factors that affect the properties of bamboo and is assessed based on Equation 4 [46].

$$
M C \%=\frac{\text { weight of moist bamboo }- \text { weight of oven drybamboo }}{\text { weight of oven dry bamboo }} \times 100 \%
$$

It is important to note that moisture content varies from top to bottom of the culm as well as throughout the thickness, with the inner wall having the highest moisture content [46]. The moisture content can range anywhere from $0-200 \%$ with the standard average moisture content being 12\% [46]. The data shown in Table 3 shows how the physical and mechanical properties change based on the distance from the base and distance from the inside of the culm [38].

Although the data in Table 3 is said to be taken at a moisture content of $9.7 \%$, it is important to note that this value is just an average. The reason for this is the moisture content is not homogenous throughout the culm as can be seen by the density value. The inner part of the culm is shown to have a higher density than the outer layer, due to its

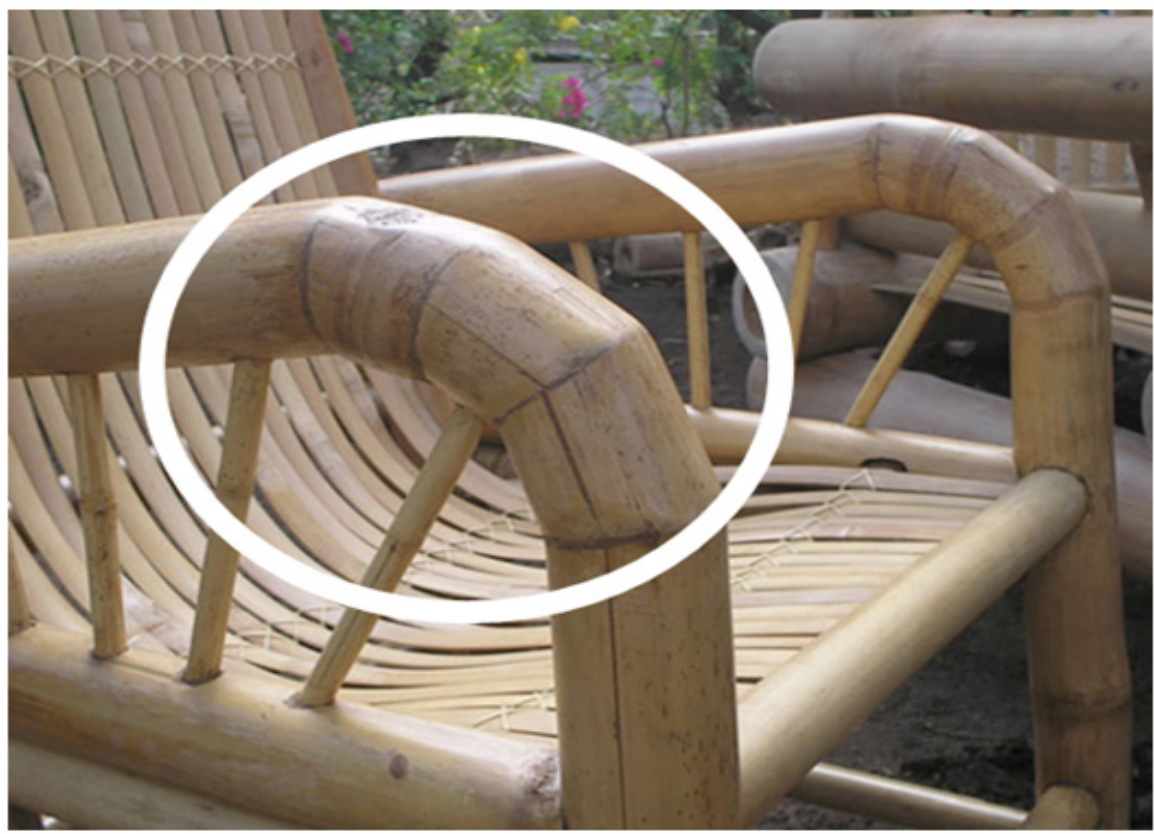

Figure 15: Bamboo chair that utilized the heat bending process [45].

\begin{tabular}{|l|l|l|l|l|}
\hline Height from Base $(\mathrm{m})$ & Layer & Density $\left(\mathrm{g} / \mathrm{cm}^{3}\right)$ & Tensile Young's Modulus $(\mathrm{GPa})$ & Tensile Strength $(\mathrm{MPa})$ \\
\hline 1.3 & 1 & 0.553 & 9 & 115.3 \\
\hline 1.3 & 2 & 0.566 & 9.8 & 115.9 \\
\hline 1.3 & 3 & 0.607 & 13.3 & 132.7 \\
\hline 1.3 & 4 & 0.632 & 14.7 & 179.1 \\
\hline 1.3 & 5 & 0.712 & 19.3 & 228.8 \\
\hline 1.3 & 6 & 0.942 & 26.3 & 281.9 \\
\hline 4 & 1 & 0.572 & 10.3 & 111.5 \\
\hline 4 & 2 & 0.630 & 12.9 & 118.7 \\
\hline 4 & 3 & 0.633 & 15.1 & 148.2 \\
\hline 4 & 4 & 0.725 & 16.8 & 175 \\
\hline 4 & 5 & 0.855 & 21.8 & 204.3 \\
\hline 4 & 6 & 1.006 & 27.4 & 309.3 \\
\hline
\end{tabular}

Table 3: Physical and Mechanical Properties of Phyllostachys Edulis (Moso) Bamboo at a Moisture Content of 9.7\% [38]. 
Citation: Carnrike T, Egoh A, Reed KS, Kalu PN (2020) Bamboo Usage in Orthopedic: An Attempt to Reconcile Materials Properties with the Biomechanics of Human Walking. Int J Phys Ther Rehab 6: 164. doi: https://doi.org/10.15344/2455-7498/2020/164

Page 13 of 14

\begin{tabular}{|l|l|l|l|l|l|}
\hline Species & Location Grown & Density $\left(\mathrm{g} / \mathrm{cm}^{3}\right)$ & Young's Modulus $(\mathrm{GPa})$ & Tensile Strength $(\mathrm{MPa})$ & ${\text { Fracture Toughness }\left(\mathrm{MPa}{ }^{\star} \mathrm{m}^{1 / 2}\right)}^{\text {(M) }}$ \\
\hline $\begin{array}{l}\text { Phyllostachys edulis } \\
\text { (Moso) }\end{array}$ & $\begin{array}{l}\text { Georgia and } \\
\text { South Carolina }\end{array}$ & $0.553-1.0$ & $9-27.4$ & $111.5-309.3$ & $\sim 56.8$ \\
\hline $\begin{array}{l}\text { Arundinaria tecta } \\
\text { (Switch Cane) }\end{array}$ & $\begin{array}{l}\text { Southern and } \\
\text { eastern United } \\
\text { States }\end{array}$ & $\sim 0.60-0.70$ & 19.60 & 103 & 40.8 \\
\hline $\begin{array}{l}\text { Phyllostachys } \\
\text { bambusoides(Giant } \\
\text { Timber) }\end{array}$ & $\begin{array}{l}\text { California and } \\
\text { south eastern } \\
\text { United States }\end{array}$ & 0.73 & 13.2 & 120 & 47.6 \\
\hline
\end{tabular}

Table 4: Properties of some Bamboo species grown in the United States with a $15 \pm 5 \%$ moisture content [47-50].

high moisture content. It can also be seen that the outer layer of the culm is the stiffest and strongest as its Young's Modulus and Tensile Strength are higher. Additionally, the data taken from the samples further from the base $(4 \mathrm{~m})$ possess higher strength and stiffness properties than those taken closer to the base $(1.3 \mathrm{~m})$ due to their lower moisture content.

Table 4 contains the properties of well-known bamboo species, near standard moisture content, grown in the United States, where the primary exoskeleton and prosthetic market is [46-49].

\section{Conclusion}

It was previously found that bamboo is the best replacement for Duralumin for exoskeleton applications. Upon performing an extensive assessment, it was confirmed that bamboo is the best replacement as it is cheaper, lighter, has reasonable formability, and has superior fracture toughness properties to that of Duralumin, which appropriately satisfy the mechanical requirements needed to counteract the demands of the ground reaction force for the safe and effective transfers of body weight during stance limb loading. Additionally, bamboo's suitability to preserve both sagittal and frontal plane kinematics for knee joint stability during single-limb stance was determined to be an important functional element for prosthetic exoskeleton design and its usage for basic orthopedic applications. Further investigation into the properties and dimensions of different bamboo species, available in the United States, indicated that each of these species were able to satisfy the exoskeleton and prosthetic material requirement as their strength properties exceeded the stress applied by the user.

\section{Competing Interests}

The authors declare that they have no competing interests.

\section{Author's Contributions}

Talya Carnrike: Acquisition and data Analysis I and drafting the manuscript.

Aruoture Egoh: Acquisition and data Analysis II and drafting the manuscript.

Kischa S. Reed: Drafting and revising manuscript.

Peter N. Kalu: Drafting, revising manuscript and final approval for manuscript to be sent out.

\section{References}

1. Gait disorders (2019) Clinical Gate.
2. Fréz AR, Daniel CR, Kerppers II, Ruaro JA, da Luz JP, et al. (2016) Incorporating environmental factors in gait assessments of persons following amputation. Fisioter em Mov 29: 113-120.

3. Cost of a Prosthetic Leg - Consumer Information

4. Robotic Exoskeletons Are Changing Lives in Surprising Ways.

5. Reed KS, Kalu PN (2016) An Assessment of Bamboo as a Potential Low-Cost Material for Exoskeleton Design in Normal Walking International Journal of Physical Therapy \& Rehabilitation 2: 1-6.

6. Types and Classifications of Exoskeletons Exoskeleton Report.

7. Pina DS, Fernandes AA, Jorge RN, Gabriel J (2018) Designing the mechanical frame of an active exoskeleton for gait assistance. Spec Issue Artic Adv Mech Eng 10: 1-8.

8. Kuster M, Sakurai S, Wood GA (1995) Kinematic and kinetic comparison of downhill and level walking. Clin Biomech 10: 79-84.

9. Souit C, Coelho DS, Szylit M, Camargo-Junior F, Cortez Junior MP, et al. (2016) Design of a lower limb exoskeleton for experimental research on gait control. In Proceedings of the IEEE RAS and EMBS International Conference on Biomedical Robotics and Biomechatronics.

10. Zhang D, Ren Y, Gui K, Jia J, Xu W (2017) Cooperative Control for A Hybrid Rehabilitation System Combining Functional Electrical Stimulation and Robotic Exoskeleton. Front Neurosci 11: 725

11. Standing tall.

12. A new budget exoskeleton could help paraplegics walk at a drastically lower price. ExtremeTech.

13. Indego. Exoskeleton Report.

14. Ekso GT-Exoskeleton Report.

15. Exoskeletons explained. Reuters.

16. Rex Bionics Exoskeleton. Servo Magazine.

17. PHOENIX Medical Exoskeleton. SuitX.

18. Perry J (1992) GAIT Pathological Function.

19. Neumann DA (2010) Kinesiology of the musculoskeletal system: foundations for rehabilitation. Mosby/Elsevier.

20. Assessment of Gait. Clinical Gate.

21. Neptune RR, Kautz SA, Zajac FE (2001) Contributions of the individual ankle plantar flexors to support, forward progression and swing initiation during walking. J Biomech 34: 1387-1398.

22. Gough M, Jenkinson A, O'Brien T (1997) A three-dimensional analysis of the ground reaction force vector patterns in normal and pathological gait. Gait and Posture 6: 266-267.

23. Svoboda Z, Bizovska L, Janura M, Kubonova E, Janurova K, et al. (2017) Variability of spatial temporal gait parameters and center of pressure displacements during gait in elderly fallers and nonfallers: A 6-month prospective study. PLoS One 12: e0171997.

24. Rabuffetti M, Recalcati M, Boccardi S (2006) Innovative rear-foot linkedbody model applied to the analysis of normal gait at different speeds. Gait Posture 24: 133-134.

25. Ellexson T, Nawrocki C, Schober D (1995) Normal Kinetic Patterns of the Lower Extremities During Natural Walking in Children Aged Six to Ten.

26. Boccardi S, Pedotti A, Rodano R, Santambrogio GC (1981) Evaluation of muscular moments at the lower limb joints by an on-line processing of kinematic data and ground reaction. J Biomech 14: 35-45. 
Citation: Carnrike T, Egoh A, Reed KS, Kalu PN (2020) Bamboo Usage in Orthopedic: An Attempt to Reconcile Materials Properties with the Biomechanics of Human Walking. Int J Phys Ther Rehab 6: 167. doi: https://doi.org/10.15344/2455-7498/2020/167

27. Fry A (2017) Normal and Abnormal Gait.

28. Seymour R (2002) Prosthetics and orthotics: lower limb and spinal. Lippincott Williams \& Wilkins.

29. Ashby MF, Ash MF (1992) Materials Selection Mechanical Design in Second Edition. British Library Cataloguing in Publication Data Library of Congress Cataloguing in Publication Data. Pergamon Press Ltd.

30. Dural ${ }^{\circledR}$ - Aluminium/Copper/Magnesium. Goodfellow.

31. ASM Material Data Sheet.

32. Carbon/Epoxy Composite Materials. Properties-Supplier Data by Goodfellow.

33. Carbon Fiber Composite Design Guide.

34. China Aisi 4130 Alloy Steel, Aisi 4130 Alloy Steel Manufacturers, Suppliers, Price.

35. Schafer RC (1987) Clinical biomechanics: musculoskeletal actions and reactions. Williams \& Wilkins.

36. Basu B (2017) Introduction to Biomechanics and Orthopedic Device Testing

37. Ichikawa K (2000) Functionally graded materials in the 21st century: a workshop on trends and forecasts. pp. 103-205.

38. Yu HQ, Jiang ZH, Hse CY, Shupe TF, Shupe CY (2008) Selected Physical and Mechanical Properties of Moso Bamboo (Phyllostachys Pubescens).

39. Forest Service U, Products Laboratory F (2010) Wood Handbook, Wood as an Engineering Material.

40. Wei X, Zhou H, Chen F, Wang G (2019) Bending Flexibility of Moso Bamboo (Phyllostachys Edulis) with Functionally Graded Structure. Materials 12 2007.

41. Schuerch C (1963) Plasticizing wood with liquid ammonia. Ind Eng Chem 55: 39.

42. Home / Learn Steam Bending.

43. Ritter M. (1990) Timber Bridges: Design, Construction, Inspection, and Maintenance. In Timber Bridges: Design, Construction, Inspection, and Maintenance. Washington, DC. pp. [3-1] - [3-62]

44. How to Bend Bamboo for a Walking Cane.

45. How to Bend Bamboo. Guadua Bamboo.

46. Okhio CB, Waning JE, Mekonnen YT (2011) An Experimental Investigation of the Effects of Moisture Content on the Mechanical Properties of Bamboo and Cane.

47. Janssen JJA (1991) Mechanical properties of bamboo. Kluwer Academic Publishers

48. Dixon PG, Gibson LJ (2014) The structure and mechanics of Moso bamboo material. J R Soc Interface 11: 99.

49. Gutu, T (2013) A study on the mechanical strength properties of Bamboo to enhance its diversification on its utilization. International Journal of innovative Technology and exploring Engineering 2: 314-319.

50. Bamboo resources and utilization in China - Fu Maoyi. 